\title{
Lecompte operation: Is it still a viable option for truncus arteriosus?
}

\author{
Chun Soo Park, MD, ${ }^{\mathrm{a}}$ Won-Kyoung Jhang, MD, ${ }^{\mathrm{a}}$ Jae-Kon Ko, MD, ${ }^{\mathrm{b}}$ Young-Hwue Kim, MD, ${ }^{\mathrm{b}}$ and Tae-Jin Yun, MD, PhD, ${ }^{\mathrm{a}}$ \\ Seoul, Republic of Korea
}

$\mathcal{B}$ Supplemental material is available online.

The Lecompte operation is not widely adopted for patients with truncus arteriosus because the anteriorly translocated pulmonary trunk may be compressed by the large truncal artery. Two babies (6 and 37 days old) with type I truncus arteriosus (Figure E1, A) underwent the Lecompte operation with technical modifications to overcome this problem.

\section{TECHNIQUE}

Under moderate hypothermic cardiopulmonary bypass, the truncal artery and both pulmonary arteries were dissected extensively, and the pulmonary arteries were occluded with snares. The truncal artery was crossclamped and blood cardioplegic solution was delivered antegradely. A vertical incision was made on the anterior wall of the right ventricle, and the ventricular septal defect was closed with a Dacron patch through this incision (Figure E2, A). The truncal artery was transected at the level of the upper margin of the pulmonary arterial origin, and a cylindrical segment incorporating the pulmonary trunk was cut off the truncal artery with direct vision of the sinotubular junction of the truncal artery (Figure 1, A). After the Lecompte maneuver, the divided ends of the truncal artery were reanastomosed and the crossclamp was released (Figure 1, B). Under beating heart conditions, the cylindrical segment of the truncal artery was cut in the middle, and truncal artery tissue flaps were used to form the posterior wall of the neopulmonary artery (Figure 2, A). The neopulmonary artery was then approximated and secured to the superior margin of the right ventriculotomy (Figure $2, B$ ), and a pulmonary allograft monocusp patch was used for anterior augmentation of the right ventricular outflow tract (Figure E2, B).

From the Divisions of Pediatric Cardiac Surgery ${ }^{\mathrm{a}}$ and Pediatric Cardiology, ${ }^{\mathrm{b}}$ Asan Medical Center, College of Medicine, University of Ulsan, Seoul, Republic of Korea.

Received for publication Nov 1, 2007; revisions received Dec 17, 2007; accepted for publication Dec 22, 2007.

Address for reprints: Tae-Jin Yun, MD, PhD, Divisional Head, Division of Pediatric Cardiac Surgery, Asan Medical Center, 388-1 Poongnap-dong, Songpa-gu, Seoul, Republic of Korea, 138-736 (E-mail: tjyun@amc.seoul.kr).

J Thorac Cardiovasc Surg 2008;136:1384-6

$0022-5223 / \$ 34.00$

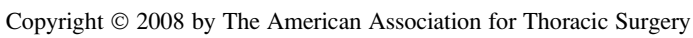
doi:10.1016/j.jtcvs.2007.12.074

\section{RESULTS}

The postoperative course of the first infant ( 6 days old at operation) was complicated by capillary leak syndrome, and the infant was discharged home 2 months after the operation. Postoperative cardiac computed tomography showed a posteriorly displaced truncal artery with a nonobstructive right ventricular outflow tract and pulmonary arteries (Figure E1, B). Echocardiography 12 months postoperatively showed no significant stenosis or insufficiency at the level of the monocusp, which was still mobile. The postoperative course of the second infant (37 days old at operation) was uneventful, and postoperative echocardiography showed grade 1 regurgitation at the level of the monocusp without significant stenosis.

\section{COMMENTS}

Since the first successful surgical correction of truncus arteriosus by McGoon, Rastelli, and Ongley, ${ }^{1}$ the Rastellitype repair has become a procedure of choice for this rare anomaly in many cardiac programs. However, a shortage in supply of adequately sized allografts and, more importantly, the problems associated with the use of an extracardiac conduit in very small infants have been major limitations of this approach. The advent of the bovine jugular vein graft (ie, Contegra, Medtronic, Inc, Minneapolis, Minn) has resolved the limited availability of small-sized conduits, but the need for early reoperation after the placement of a small graft does not seem to be alleviated by the use of this new bioprosthetic conduit. ${ }^{2}$ In 1982, Lecompte and associates ${ }^{3}$ introduced a novel surgical technique for the repair of various complex congenital heart anomalies, which is now called the Lecompte operation. In the original report, Lecompte applied this technique to 4 patients with truncus arteriosus. Ever since this epochal report by Lecompte himself, there have been only a few clinical reports regarding the Lecompte operation for truncus arteriosus. ${ }^{4}$ Given that neonates or young infants with truncus arteriosus can be best benefited from this technique because Rastellitype repair is deemed most undesirable for small infants, this rare clinical application may fall far short of what can be expected. One of the reasons that the Lecompte operation did not gain favor in truncus arteriosus repair might be the possibility of compression and strangulation of the pulmonary trunk by the large and prominent neoaortic root. ${ }^{5}$ Our surgical technique alleviates the excessive tension on the pulmonary trunk by (1) resecting a cylinder off the 


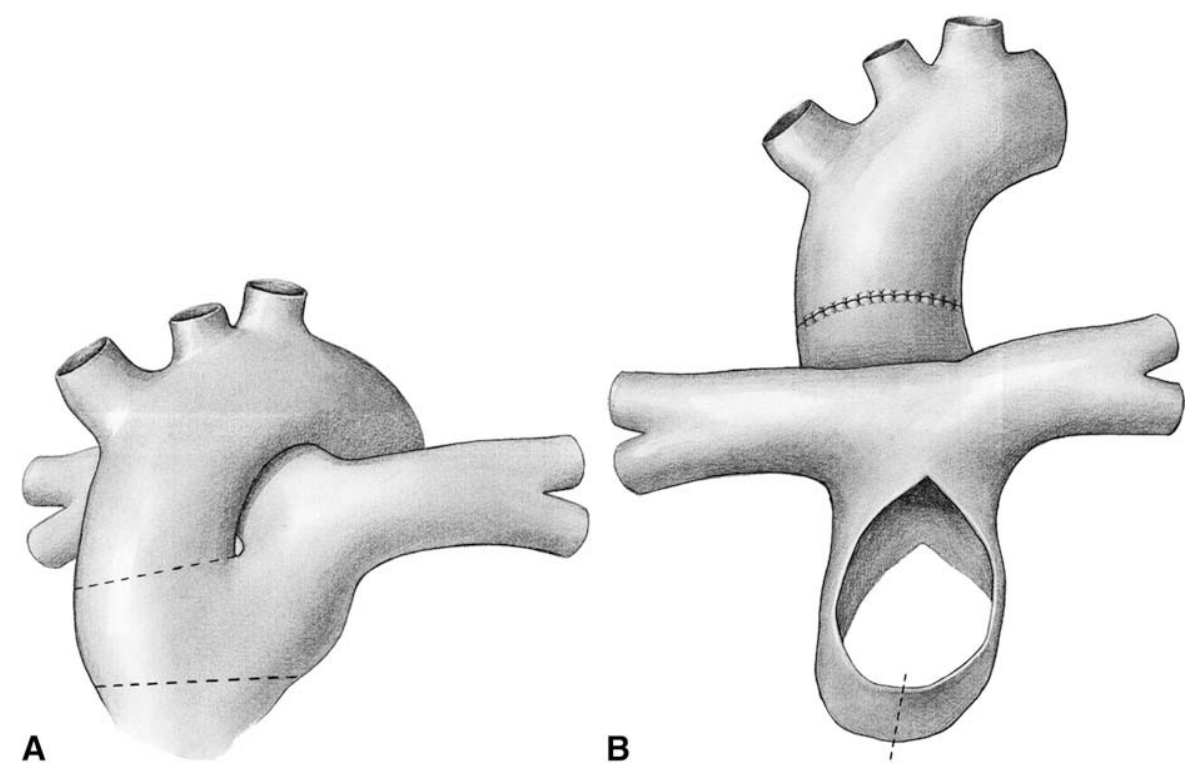

FIGURE 1. A, A cylindrical segment of truncal artery incorporating the pulmonary trunk is cut off the truncal artery along the dotted lines. B, The pulmonary trunk is translocated anteriorly, and the divided ends of the truncal artery (neoaorta) are reanastomosed. The cylindrical segment is cut in the middle along the dotted line.
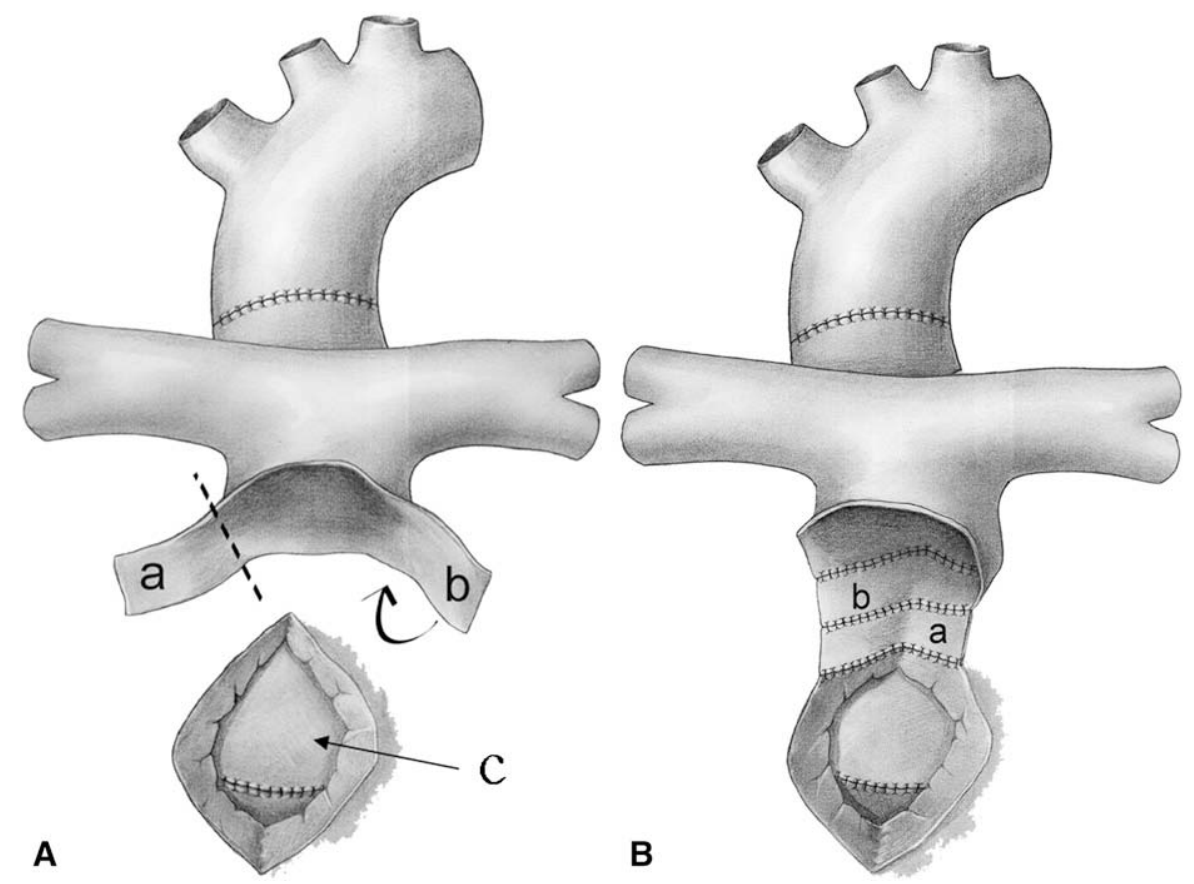

FIGURE 2. A, Flap $a$ is cut off along the dotted line, and flap $b$ is directly sutured to the back wall of the pulmonary trunk. The ventricular septal defect is closed with a Dacron patch $(c)$. B, Flap a is sutured to flap $b$, forming the posterior wall of the pulmonary trunk. This newly reconstructed pulmonary trunk is approximated and secured to the superior margin of the right ventriculotomy.

tuncal artery, which makes the neoaortic root shorter and more posteriorly positioned, and (2) lengthening the posterior wall of the pulmonary trunk using truncal artery tissue flaps. Degeneration of the allograft monocusp valve with the development of pulmonary regurgitation and deterioration of right ventricular function could be a caveat of this new technique, which needs to be defined from a longer term follow-up. 


\section{References}

1. McGoon DC, Rastelli GC, Ongley PA. An operation for the correction of truncus arteriosus. JAMA. 1968;205:69-73.

2. Sinzobahamvya N, Asfour B, Boscheinen M, Photiadis J, Fink C, Schindler E, et al. Compared fate of small-daimeter Contegras and homografts in the pulmonary position. Eur J Cardiothorac Surg. 2007;32:209-14.
3. Lecompte Y, Neveux JY, Leca F, Zannini L, Tu TV, Duboys Y, et al. Reconstruction of the pulmonary outflow tract without prosthetic conduit. J Thorac Cardiovasc Surg. 1982;84:727-33.

4. Nakae S, Kawada M, Kasahara S, Kuroyama N, Hiraishi S, Yoshimura H. Correction of truncus arteriosus with autologous arterial flap in neonates and small infants. Ann Thorac Surg. 1996;62:123-9.

5. Haydar S. Lecompte maneuver in truncus arteriosus repair: potential risks! Ann Thorac Surg. 1996;62:1241.

\title{
Pediatric Application of the Thoratec CentriMag BiVAD as a Bridge to Heart Transplantation
}

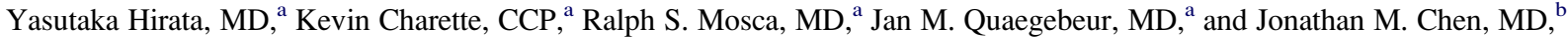 \\ New York, NY
}

The Thoratec CentriMag ventricular assist device (VAD) (Thoratec Corporation Pleasanton, Calif) (Figure 1) is a centrifugal pump designed for extracorporeal support that operates without mechanical bearings or seals. Although extracorporeal membrane oxygenation (ECMO) provides cardiac and respiratory support in a rapid manner for the pediatric patient population, it offers only short-term support with an increase in complications beyond the second week. The CentriMag system has advantages over other systems: the pumps have a low priming volume and low requirements for heparin and hemolysis. We report three successful applications of the CentriMag BiVAD as a bridge to pediatric heart transplantation.

\section{CLINICAL SUMMARIES}

PATIENT 1. A 7-year-old previously healthy boy with a 10day history of abdominal symptoms was brought to the emergency department initially stable, but his condition deteriorated and later necessitated intubation and full cardiac support; his oxygen saturation decreased to $40 \%$. Echocardiographic analysis revealed severely decreased left ventricular function. The heart arrested in the operating room before incision and cardiopulmonary bypass was instituted as an emergency measure. A malleable $28 \mathrm{~F}$ lighthouse tip

From the Division of Cardiothoracic Surgery, Department of Surgery, Columbia University College of Physicians and Surgeons, ${ }^{a}$ and the Department of Cardiothoracic Surgery, Joan and Sanford Weill Medical College of Cornell University, ${ }^{\text {b }}$ New York, NY.

Received for publication Nov 1, 2007; revisions received Feb 29, 2008; accepted for publication May 4, 2008.

Address for reprints: Yasutaka Hirata, MD, Pediatric Cardiac Surgery, Columbia University College of Physicians and Surgeons, New York, NY (E-mail: yh2240@ columbia.edu).

J Thorac Cardiovasc Surg 2008;136:1386-7

$0022-5223 / \$ 34.00$

Copyright (c) 2008 by The American Association for Thoracic Surgery doi:10.1016/j.jtcvs.2008.05.028

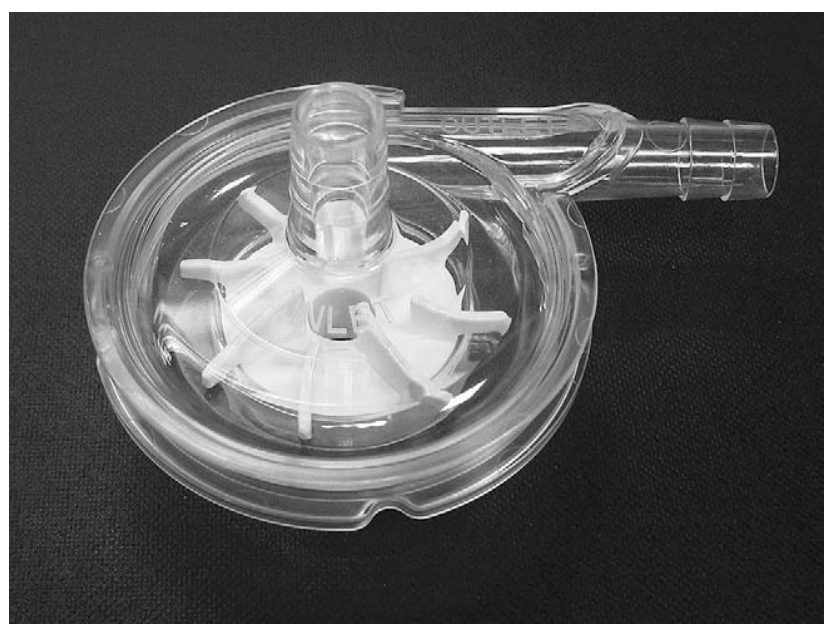

FIGURE 1. CentriMag pump.

cannula (Medtronic, Inc, Minneapolis, Minn) was placed through an incision along the costal margin at a point just inferior to the approximate site of the left ventricular apex. Two concentric purse-string sutures of 3-0 Prolene polypropylene (Ethicon, Inc, Somerville, NJ) supported with bovine pericardial pledgets were placed around the left ventricular apex, and the inflow cannula was placed into the left ventricle. Two 14F Biomedicus cannulas (Biomedicus, Inc, Eden Prairie, Minn) were similarly placed through two incisions along the epigastrium and inserted into the ascending aorta and main pulmonary artery. A 24F malleable lighthouse tip cannula was placed through an incision along the right thoracic wall, and the inflow cannula was placed into the right atrium, directed toward the inferior vena cava. Heparin was started at 24 hours to maintain an activated clotting time of 160 to 180 seconds. Because of pulmonary edema and desaturation, an oxygenator was inserted in-line with the right VAD outflow and was removed after 24 hours once his 

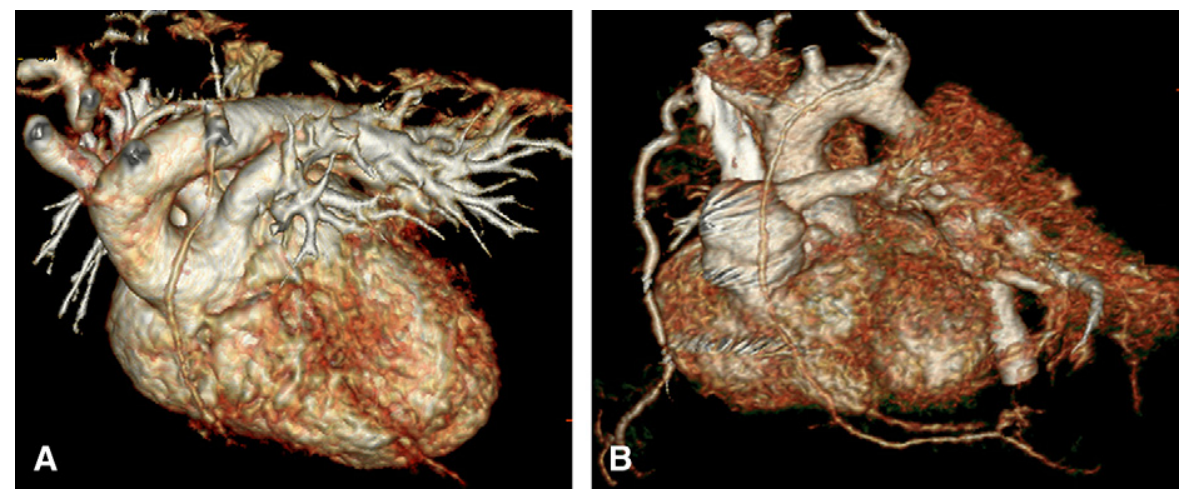

FIGURE E1. A, Preoperative cardiac computerized tomographic volume rendering images of case 1 showing type 1 truncus arteriosus. B, Postoperative images of case 1 showing posteriorly displaced neoaortic root and anteriorly translocated neopulmonary trunk. 


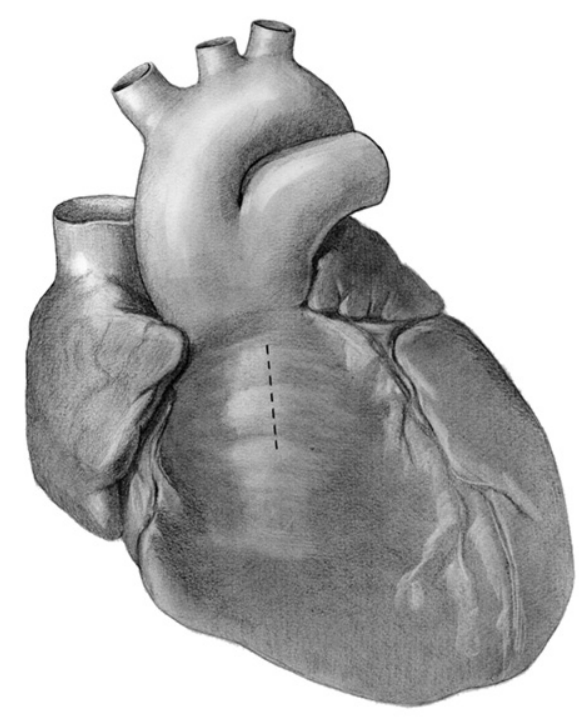

\section{A}

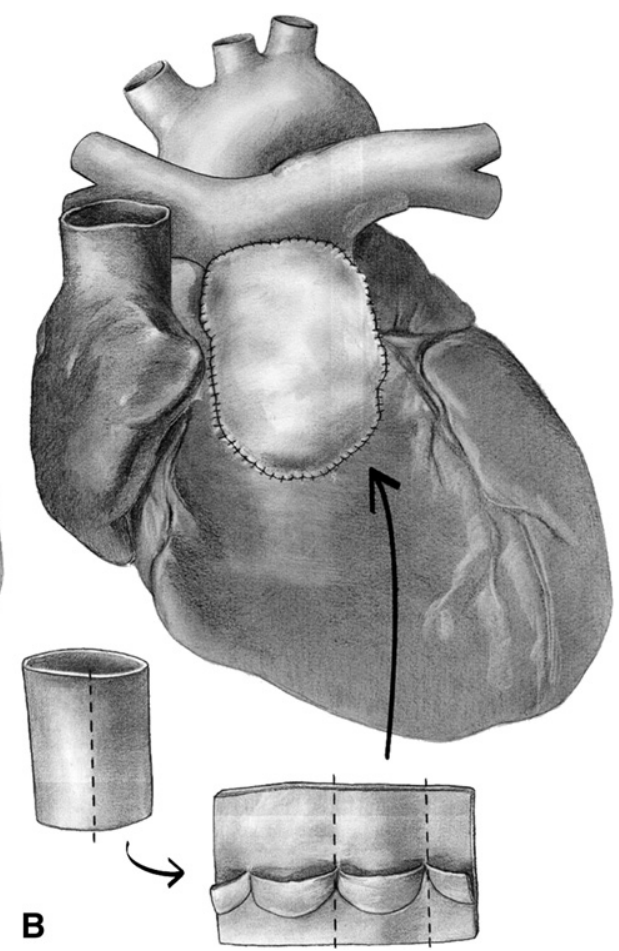

FIGURE E2. A, A right ventriculotomy is made along the dotted line. B, The right ventricular outflow tract is depicted after the completion of the procedure. A pulmonary allograft monocusp patch is placed as an anterior patch of the right ventricular outflow tract. 